\title{
La crítica de
}

\section{Kierkegaard a la fe}

cristiana del"Todo es

posible" en Temor $y$

temblor y El concepto de la angustia

\section{The Kierkegaard's}

criticism to the christian faith

of the "Everything is possi-

ble" in Fear and Trembling

and The Concept of Anxiety

\section{Magdiel Martínez Gómez*}

Pontifícia Universidade Católica do Rio Grande do Sul, Brasil 


\title{
Resumen
}

El pensamiento de Søren Kierkegaard ha sido vastamente trabajado, en torno al concepto de fe y, a su vez, aparece que es una fe ceñida a la interpretación bíblica del cristianismo. Por ello, es frecuente encontrar a Kierkegaard como un pensador cristiano-religioso que, lejos de tomar distancia crítica de la fe, la sigue hasta sus últimas consecuencias y justificación. Sin embargo, por medio de la conexión argumentativa entre dos escritos de Kierkegaard: Temor y temblor y El concepto de la angustia se articularán dos tesis que exponen críticas a la fe. En Temor y temblor, el cuestionamiento aparece cuando la religión cristiana parece desafiar al ser humano con la idea de que "todo es posible", al transformar la muerte de la ética; es decir, la muerte de Isaac a manos de Abraham, en un sacrificio de fe. En El concepto de la angustia, la crítica sobreviene nuevamente cuando la premisa de la fe, según la cual para Dios todo es posible, quiere vivir en la inocencia de las categorías éticas del bien y del mal. En conclusión, la crítica de Kierkegaard se dirige a la fe del "todo es posible" y tiene como base presuposiciones éticas.

Palabras clave: Kierkegaard, crítica, fe cristiana, ética, sacrificio de Isaac, el bien y el mal.

\begin{abstract}
Søren Kierkegaard's thinking has been worked around the concept of faith. He appears as a religious writer for adjusting this concept to the biblical interpretation of Christianity. In this sense, it is common to find Kierkegaard as a Christian thinker who, far from taking critical distance from faith, follows faith to its ultimate consequences and justification. However, through the argumentative connection between two writings of Kierkegaard, such as: Fear and
\end{abstract}


* Magdiel Martínez Gómez, filósofo colombiano, cuenta también con estudios de Pedagogía. Actualmente cursa una maestría en Filosofía en la Pontifícia Universidade Católica do Rio Grande do Sul, Brasil.

** Este artículo fue realizado con apoyo del Consejo Nacional de Desenvolvimiento Científico y Tecnológico de Brasil. 
trembling and The concept of anxiety, two thesis that expose criticisms of faith will be articulated. In Fear and trembling, the criticism lies in the moment that the Christian religion establishes things, in such a way, that it is imperative to look at the sky to transform the death of ethics; that is, the death of Isaac under the hands of Abraham, in a sacrifice and attain faith. In The concept of anxiety, criticism comes when the premise of faith, according to which, for God "everything is possible", wants to live in the innocence of the ethical categories of good and evil. In conclusion, Kierkegaard's critique of faith is based on ethical presuppositions.

KeYwords: Kierkegaard, criticism, Christian faith, ethics, sacrifice of Isaac, good and evil.

\section{Introducción}

El asunto de la fe en Kierkegaard ${ }^{1}$ barrunta giros inesperados, lo más pertinente sería estudiarlo bajo una perspectiva evolutiva. Lo más constante es el abordaje de la fe en relación o en discusión con las escrituras cristianas; lo inconstante está en las ideas usadas por Kierkegaard para determinar el concepto. Sobre lo último, por ejemplo, encontramos con D. González que la fe: "As an absolute passion able to annul incertitude, Christian faith has also to do with the historicity of an event". ${ }^{2}$ En ese or-

1 En adelante, SKS (Søren Kierkegaard Skrifter) será la edición crítica en danés de las obras de Søren Kierkegaard, según la última edición de sus obras completas. Se citará indicando las abreviaciones de la obra original y la paginación. Las referencias anteriores a SKS serán las versiones en español. Por lo demás, en las citaciones la letra K será la abreviación de Kierkegaard.

2 Traducción libre: "Como una pasión absoluta, la fe es capaz de anular la incertidumbre, la fe cristiana también tiene que ver con la historicidad de un acontecimiento". Darío. González, "Kierkegaard's Skepticism”, en A Companion to Kierkegaard Jon Stewart, ed. (Nueva Jersey: Wiley Blackwell, 2015), 134. 
den de ideas, encontramos que la fe, como pasión, es la certeza que va hasta lo último de la Tierra, sin importar el riesgo de las cosas que deja. Como acontecimiento histórico, introduce la encarnación de Cristo (el Dios eterno en el tiempo) como piedra angular que disemina todas las contradicciones/paradojas en el mundo. La fe también se vincula con el hecho escandaloso de que para Dios "todo es posible" 3 (en danés, for Gud er Alting muligt), cosa que implica su poder creador ex nibilo (de la nada), su libertad absoluta y su ser eminentiae por encima de los principales límites conocidos: lo bello, lo bueno y lo verdadero. Así que, por lo menos, parecen existir tres ideas para determinar la fe.

Ahora bien, ¿podrá ocurrir que las tres ideas sean, en esencia, una sola y la misma? Es válido decir que hasta cierto punto tienen correlación, pues la encarnación de Cristo requiere que para Dios todo sea posible, y ambas demandan de la pasión del creyente. No obstante, cuando al filo del detalle se compara la paradoja de la encarnación de Cristo con el hecho de que para Dios todo es posible, surgen consecuencias muy diferentes que vale la pena notar. La paradoja implica que, a pesar de ir más allá la razón, se retorna a ésta, y en este vértigo de idas y vueltas, la fe se realiza en una síntesis de términos opuestos, dominada por una "estructura" que los une por aquello que cada uno pierde en la relación. En cambio, que para Dios todo sea posible exhorta a alcanzar las alturas encumbradas del concepto de posibilidad, el cual no tiene nada en común con la síntesis de opuestos o la estructura paradojal entre el bien y el mal, tiempo y eternidad, cuerpo y alma, etcétera. En concreto, la sustancial y radical diferencia estriba en lo siguiente: mientras que el fenómeno específico de la encarnación de Cristo levanta posibilidades que, con todo, están dentro de los límites de estructuras insoslayables 
de relación, contrariedad, dialéctica; no sucede lo mismo con el Dios de lo posible, que puede hacer literalmente cualquier cosa de la nada (ex nibilo creans omnia) sin restricción y por encima de las estructuras; todo, absolutamente todo, le es posible.

Hechas las diferencias y aclaraciones, salta a la vista que la pretendida crítica de Kierkegaard a la fe no es en absoluto una crítica a la fe en general o a las múltiples ideas que determinan el concepto. El objetivo de este escrito es profundizar y ceñirse a la crítica que se extiende sobre una idea específica de la fe. Por tanto, de las tres ideas resultantes, y en vista de que hay fundamento para una clasificación o "pensarlas distintamente", se sigue que la crítica de Kierkegaard a la fe apunta solamente hacia la potentia divina para la cual todo es posible.

Vale mencionar, también, que esta crítica tiene como base presuposiciones éticas. Por "presuposiciones" entiéndase aquello que no cabe dentro de los objetivos de una profundización sobre el tópico de la ética, más allá de sugerirla en el horizonte y conducirnos hacia ella. El tema de la ética aparece solamente y con relación al objetivo perseguido, el cual es determinar la existencia y articular explicativamente la crítica a la fe del "todo es posible". En efecto, no nos ocupa la ética de Kierkegaard o dilucidar sus conceptos, sino hasta donde sea necesario para dejar en claro su crítica a la fe. No obstante, es importante poner en relieve dos asuntos de su ética, para entrever algunas implicaciones de fondo a lo largo del texto, que lo enriquecen.

El primero de ellos es mencionar que la ética en Kierkegaard es la representación máxima y más coherente de la racionalidad y, en cuanto tal, es la manera como él decide abordar la instancia racional del ser humano. La razón es ética y se desarrolla éticamente. De ahí que la amplia y tan aceptada teoría de "los tres estadios", deducida sobre todo de su obra La alternativa y Etapas en el camino de la vida, (Enten-eller y Stadier paa Livets $V e i)$, establece que el movimiento dialéctico o contrario en relación con la pura estética, no es el puesto ocupado por la razón en la historia 
clásica de las ideas, sino el estadio ético. Lo dicho también puede verificarse en la persistente "crítica kantiana de Kierkegaard"“a la razón pura, para exhortarla a tornarse más concreta, más real, cosa que, para el danés, corresponde con ser más ética. Los hechos muestran que Kierkegaard no dispuso alejarse de la razón, sino que decidió tratarla éticamente. Lo anterior se verifica en lo siguiente: "Porque la Ética es aun una ciencia ideal, y esto no solamente en el sentido en que toda ciencia lo es. La Ética quiere introducir la idealidad en la realidad, es decir, que su movimiento no es como el de otros casos, en los que se pretende elevar la realidad hasta la idealidad". 5

Queda claro, pues, que la ética es, trabaja y pertenece a la instancia de la idealidad. Con el término idealidad, Kierkegaard entiende en El concepto de la angustia el "idealismo alemán" (Hegel y sus interlocutores: Kant, Fichte, Schelling) que, según él, es fuente y lugar para la lógica y el pensamiento científico, atributos innegables de la racionalidad. Entonces, la ética no es otra cosa que la razón, con el atenuante de que es el momento o la vía más coherente, concreta y real de la racionalidad, contrapuesta a sus otros instantes más intelectuales, como la lógica pura. Por ende, en Kierkegaard la idealidad es la ética y, al mismo tiempo, la ética es la idealidad más concreta y coherente.

Puesta en perspectiva en la racionalidad de la ética está lo que algunos intérpretes ${ }^{6}$ han denominado la "primera ética" y la "segunda ética" de Kierkegaard, análisis que se deduce tanto implícita (como en la citación ya hecha) como explícitamente. ${ }^{7}$ La primera ética corresponde a las éticas

Ver K. 2008, 155. SKS, SD, 231.

K. 2007, 58-59. SKS, BA, 323-324.

A este respecto es pertinente estudiar el artículo de Arne Grøn: "La ética de la repetición", Enrahonar: quaderns de filosofia, vol. 29 (1998); 38-45.

Ver K. 2007, 65-66. SKS, BA, 328. 
trabajadas en la historia de la filosofía; es estrictamente filosófica, con dificultad tiene contactos con la dogmática o con el campo religioso. "La primera Ética ignora el pecado". ${ }^{8}$ La segunda ética, en cambio, es propiamente la ética de Kierkegaard y su propuesta de autoría, ya que: "La nueva Ética presupone la Dogmática y con ella el pecado original [...] al mismo tiempo, que propone la idealidad como tarea".

En líneas generales, el motivo de Kierkegaard para postular conceptualmente una segunda ética estriba en su profundo interés por atrapar una "realidad" faltante, que quedaría zanjada con el pecado y los presupuestos cristianos. "Lo que el arrepentimiento muestra es justamente que el hombre fracasa ante la exigencia de la ética" ${ }^{10}$ Convencerse seriamente de que "algo no está bien en el mundo", es la cuota de "realidad" que la segunda ética gana en relación con la primera, mediante su reconocimiento del pecado. Sin embargo - y esto es lo que más importa aquínos damos cuenta que, más allá de las diferencias relacionadas con si la segunda ética parte de la realidad a la idealidad y la primera lo hace a la inversa; si la una considera presupuestos religiosos y la otra sólo filosóficos; si hay presencia del pecado o no, más allá de todo, "ambas éticas son una y la misma en el sentido de que proponen la idealidad como su tarea y su telos supremo". ${ }^{11} \mathrm{Al}$ proponer la idealidad, ahora sabemos que,

$8 \quad$ K. 2007, 71. SKS, BA, 330.

$9 \quad$ K. 2007, 66. SKS, BA, 328.

10 Grøn, "La ética de la repetición”, 41.

11 De todos modos, el asunto no deja de ser espinoso y problemático. Al respecto debe mencionarse que la lectura de Temor y temblor ha dado pie a pensar que existiría una "ética religiosa" que emana de los mandatos absolutos de Dios. Entonces, o seguimos a El concepto de la angustia y su idea de que toda ética, tanto la primera, como la segunda, tienen como telos supremo lo racional/la idealidad y no lo religioso, o suponemos que la ética es religiosa por reconocer elementos muy particulares de lo religioso, como la dogmática y el pecado. La tesis de este artículo considera pertinente seguir la idea de una "racionalidad general de la ética", porque lo religioso, con todo, no pasa de ser una "suposición” en la ética que le viene de afuera; en cambio, la idealidad es la tarea de la ética, cosa que significa en Kierkegaard la cuestión de toda una vida. 
por extensión, se plantean los postulados de la racionalidad, los cuales tienen como imagen más próxima la conocida ética de las virtudes. A su vez, nos percatamos, en última instancia, de que existe en Kierkegaard algo así como una "concepción de la ética", que nos permite hablar de lo ético sin más; esto es, indistintamente del asunto, cuando no sea el caso de enfatizar y profundizar en las diferencias.

En consecuencia, cuando se habla de la crítica de Kierkegaard a la fe del "todo es posible" y, a continuación, es dicho que tiene de base presuposiciones éticas, equivale a decir, en el fondo, que el asunto pasa estrechamente por el conflicto histórico entre la fe y la razón. El problema ha ocupado a generaciones enteras desde que se escuchó el nombre de Cristo. De modo que, la patrística, la filosofía medieval y la filosofía moderna, es decir, casi todo el pensamiento humano después del advenimiento del cristianismo ha heredado la turbación entre el verdadero creyente que dice: "lo voy a abandonar todo", o, "lo voy a ganar todo", y su amigo prudente que contesta: “ $¡$ calma, no pierdas la cabeza!”. Esta polémica entre fide y ratio resucita con Kierkegaard en los albores de nuestra contemporaneidad, sólo que la mayoría de las veces no es entre fe y razón, sino entre fe y ética, pues ya hemos explicado que el danés pensaba la razón éticamente.

Con el factor de lo racional en mente, es pertinente pasar al segundo asunto que era menester poner en relieve en lo concerniente a la ética. En este punto, lo importante es observar que la presencia de lo ético en la crítica a la fe se debe, en exclusivo, a su esencia racional. Dejemos que el filósofo ruso Ley Shestov nos explique lo anterior. Siguiendo a Kierkegaard, dice: "Desde el instante en que la razón [...] proclama su 'imposible', la ética surge de inmediato y formula su 'tú debes". ${ }^{12} \mathrm{Y}$

12 Ley Shestov, Kierkegaard y la filosofía existencial, José Ferrater Mora, trad. (Buenos Aires: Editorial Sudamericana, 1952), 62. 
puntualiza: "la razón humana no consiente en admitir que todo sea posible; esto equivaldría para ella a sumir el universo en una arbitrariedad sin límite". ${ }^{13}$ Si ello ocurre para la razón, también lo es para la ética, la cual tiene por finalidad suprema la racionalidad y surge de inmediato, según Shestov, después de los edictos de la razón.

$\mathrm{Al}$ servicio de la idealidad, la ética propende a desarrollar la naturaleza de la idea que, en cuanto tal, es lógica y no violenta, a nivel fundamental, el "sentido común"14 de la humanidad. Por su vínculo embrionario y sanguíneo con lo ideal, es entendible que la ética, en tanto que sea lo ético y no otra cosa, no admita, ni reconozca, a un ser humano que acredite en la omnipotencia divina; acreditarlo sería pensar un mundo donde es posible que las cosas ocurran "de la nada", sin estar dentro del "sentido común". A la ética le place entregarnos un mundo con límites, con imposibles, porque nos dice que, justo en ello, radica que el mundo sea nuestro mundo y no el paraíso, el cielo o, incluso, el reino de las bestias. "Roughly, the idea is that without ethical commitment, love is episodic, lacking continuity and importance, while selfhood is unbalanced and freedom is negative, empty, and arbitrary". ${ }^{15}$ Es así, con la libertad dentro del límite del sentido común, que la ética procede a descalificar la pregunta tentadora sobre si las cosas pueden ser de otra manera o, como enuncia Corintios 2, si las cosas pueden ser hechas de nuevo, inquietudes y enigmas profundos de la humanidad. Por las razones dadas, resulta inteligible

13 Shestov, Kierkegaard y la filosofía existencial, 111.

14 Entiéndase por sentido común, no su habitual significado cotidiano que implica irreflexión, sino uno más crítico, como concepto, que abarque las grandes ideas compartidas por la humanidad, las ideas universales y necesarias, tales como la vida, la muerte y otras de tal índole, fuera de las cuales es difícil concebir algo más. La expresión no es aleatoria. Resulta curioso observar que en la ética de La alternativa, nutrida ya de supuestos religiosos, como el arrepentimiento, la interioridad, la decisión, el matrimonio, el amor, etcétera, Kierkegaard usa con frecuencia la expresión: lo común, que en danés corresponde al término Almindelige.

15 Fremstedal, 2015, 113. 
que la ética esté envuelta y haga acto de presencia, al menos aquí como presupuesto, en la crítica de Kierkegaard a la fe del "todo es posible”. A lo largo del texto y en diferentes grados, la ética aparece para representar los intereses opuestos de la fe, a raíz de su poco entusiasmo con "el entendimiento que sobrepasa todo entendimiento" y, no obstante, amor ferviente por lo "común” y lo racional.

\section{Temor y temblor}

Para entrar en materia, en 1843 la obra Temor y temblor sacó a la luz la interpretación bíblica de Kierkegaard sobre el "sacrificio de Isaac" (en danés offre Isaak) a manos de Abraham. No se trataba de cualquier criatura, era lo que Abraham más amaba, el hijo que más deseaba antes de morir. El acto decisivo del sacrificio fue levantar el cuchillo y extender la mano hacia su única esperanza. Se trataba de un sacrificio, no un asesinato; un prodigio santo, no una obra del mal. Abraham no banalizaba la vida que tenía delante, ésta merecía el mismo respeto que cualquier representación humana de lo sagrado. Podríamos suponer que nunca hubiera tomado el cuchillo a no ser que algo igualmente sagrado se lo hubiera pedido. Tampoco habría que suponerlo, pues el Dios de Abraham, que escucha los murmullos y los secretos humanos, hizo que así sucediera. Ese mismo Dios que otorga la vida sagrada a todas las cosas, le solicitó a Abraham que sacrificara a su hijo. El mandato y la orden iban con indicaciones claras: había total transparencia sobre el proceso y el mecanismo del sacrificio. Lo que jamás se estableció era que la muerte sagrada reportara algún beneficio para el género humano. Desde el comienzo, sólo Abraham escuchaba la voz de Dios, era una relación secreta y oculta en la cual no había lugar para el mundo conocido. En vista del contexto, Abraham tenía tres motivos para sacrificar a Isaac: 1) por amor de un Dios invisible y misterioso (que el ojo humano no ve), 2) hacerlo sin recibir una promesa de recuperación y 3) por amor a sí mismo. 
Los motivos anteriores no son razones. Abraham sabe que esta relación secreta entre él y Dios, según el orden ético-general del mundo, es egoísta; y que nadie renuncia a lo que más ama por un Dios misterioso que no le ha prometido nada a cambio. Son razones imposibles de seguir. Si Abraham pretende sacrificar a Isaac, él requiere creer con todas sus fuerzas que "todo es posible para Dios" (en danés, for Gud er Alt muligt), que al final de todo será posible el sacrificio en lugar de un asesinato. En tal situación límite, sólo cabe entregarse a la máxima de Kierkegaard, según la cual: "Desde el punto de vista espiritual se puede decir, indudablemente, que todo es posible; pero en el mundo finito hay de seguro muchas cosas que son imposibles" ${ }^{16}$ En este orden de ideas, "Si la fe no puede santificar la acción en la que se intenta matar al propio hijo, entonces Abraham debe ser juzgado exactamente como cualquier otro hombre en el mismo caso". ${ }^{17}$ Todo dependerá de que exista la fe (en danés Tro) y que sea justamente el riesgo de creer que todo es posible y, sobre todo, la pasión de creerlo. De existir y ser lo que ella es, "sólo por la fe se asemeja uno a Abraham, en modo alguno por el crimen y el asesinato". ${ }^{18}$

Ya que Abraham requirió de la fe para el acto del sacrificio, Kierkegaard reflexiona que: "Abraham no renunció a Isaac en virtud de la $\mathrm{fe}$, sino que por ella lo obtuvo plenamente". ${ }^{19}$ Con esta nueva afirmación, Abraham no tuvo fe para abandonar a su hijo en el sacrificio; su fe estuvo en que, pese a tomar el cuchillo y extender la mano sobre Isaac, pudo volver a casa con su hijo y obtenerlo de nuevo. Es verdad, ni con el cuchillo encima, el amor de Abraham por su hijo se convirtió en el dolor 
del recuerdo o en lamentos del pasado. Pareció mantenerse rejuvenecido en la esperanza y nunca vio razón para ahogarse en lágrimas. Que el amor de Abraham no se convirtiera en la silueta de un fantasma abandonado, alimenta la idea de que Abraham abundaba en fe y creía demasiado en que el Dios de lo posible le daría nuevamente a su hijo. De acuerdo con las dos afirmaciones en conflicto, resulta acertado lo que enfatiza Green:

The central idea here is the "double movement" of faith. The first movement, "infinite resignation", is accomplished by relinquishing one's heart's desire [...] The "knight of faith" embodies the second movement. He starts where the "knight of infinite resignation" ends. ${ }^{20}$

Según la interpretación que Guerrero hace de Green, el primer movimiento de la fe "es el abandono y resignación infinita a la voluntad de Dios". ${ }^{21}$ A diferencia del primero, el segundo movimiento no concibe que Dios quiera quitar y despojar, sino que Dios, con igual poder, da, recupera y sostiene. La experiencia de lo divino como dolor y pérdida del mundo conocido es el hecho que anima la necesidad de marcar dos movimientos diferentes en el camino hacia la fe. Hechas las diferencias, en Temor y temblor comienza un devenir ascendente del primero al segundo movimiento, que sólo en su totalidad alcanzan el concepto de fe. El impulso hacia la nada y la destrucción de la primera acción, provocan un último suspiro de vida y el comienzo del movimiento infinitamente vital,

Traducción libre: “La idea central aquí es el 'doble movimiento' de la fe. El primer movimiento, la 'resignación infinita', se logra renunciando al deseo del corazón [...] El 'caballero de la fe' encarna el segundo movimiento. Él comienza donde el 'caballero de la resignación infinita” termina”. Ronald M. Green, "Developing Fear and Trembling”, en The Cambridge companion to Kierkegaard, A. Hannay y G.D. Marino, eds. (Cambridge: Cambridge University Press, 1998), 257-281.

${ }_{21}$ Luis Guerrero, coord. "Los niveles de interpretación de Temor y temblor", en Søren Kierkegaard Senderos existenciales (Ciudad de México: Sociedad Iberoamericana de Estudios Kierkegaardianos, 2013), 38. 
en relación con el cual se concentra el significado de la fe. Como apunta Green, el caballero de la fe encarna con cuerpo y espíritu la segunda acción del proceso, todo lo anterior se concreta gracias a lo segundo.

En el esquema del doble movimiento hacia la fe hay que diferenciar desde ahora un "movimiento previo a la fe" y un "movimiento de fe". Recapitulando, ciertamente Abraham recuperó a su hijo por la fe, mas también es cierto que sólo por ella podía renunciar a él. Con todo, cuando Kierkegaard comienza a contrastar el movimiento de la renuncia y el de la recuperación, sólo reconoce fe en la segunda acción. Afirma que Abraham no renunció a Isaac en virtud de la fe, sino que lo recuperó por ella.

Es notable que existe un giro conceptual. A su vez, ese giro tiene por causa que la fe, en Temor y temblor, se altera bajo una teleología ética que sobrepasa los intereses propios de la fe. En el crucial momento de formular el objetivo del libro, Kierkegaard afirma de la ética: "Por tanto, si decimos que queda suspendida teleológicamente, no queremos significar que quede sin más eliminada, sino exactamente conservada en una esfera superior que es su $\tau \dot{\varepsilon} \lambda \mathrm{o} \varsigma$ ". ${ }^{22}$ Más adelante, concluye: "Ahora bien, la historia de Abraham comporta esa suspensión teleológica de la ética". ${ }^{23}$ La misteriosa esfera superior, que corresponde a la fe cristiana, trabaja en sí y desde sí para la ética en todo momento. Esto equivale a decir que nunca toma el atrevimiento de trabajar para sí misma. La idea máxima y esencial de la religión cristiana, esto es, su telos final, no es realmente su genuino horizonte, debido a que también es el telos de la ética (en danés Ethiken). La ética, como si llegara desamparada de otro mundo, viene a robarse el fuego de la esfera superior o, con un tono menos provocador, viene a mantenerse viva con el pan de la religión. 
Premeditado el recíproco intercambio entre dos telos, entre dos esferas, es justificable que Kierkegaard mirara con ojos críticos la fe cristiana, cuando todo está dispuesto para mirar hacia al cielo, pero no a la ética. Es entendible que el danés, en los primeros pasos de la idea religiosa, reconociera y fuera consciente que sacrificar a Isaac ante un Dios invisible es un fenómeno estrictamente religioso de fe. Pero es aún más comprensible que cuando la ética se acerca demasiado para exclamar: ¡Isaac!, Kierkegaard muda sus declaraciones y niega que el sacrificio llegue a ser indicio de espíritu cristiano y de fe. Cuando la ética esté ya muy cerca, habrá que diferenciar entre "los actos de fe" y "los actos que necesitan de fe", pues los últimos llegarán a ser verosímiles en lo extraordinario, en lo extremadamente grandioso, y tendrán cualidades divinas como el silencio y la soledad, pero jamás serán la epifanía religiosa de la fe. De manera que, si el sacrificio de Isaac no es un acto de fe, al menos Kierkegaard mostró que sí necesita de fe, sólo que la fe no llegará a suplir la necesidad. En ningún momento la fe debe sentirse realizada con el llanto o la pared resanada de la ética. Para este fin, Kierkegaard elabora el esquema del doble movimiento y sitúa exclusivamente a la fe en la ascendencia hacia el segundo movimiento, basado en la recuperación de Isaac. El primero, el sacrificio, se convierte con el paso de la necesidad ética en un movimiento que no es posible dejar fuera de la transición ascendente, pero no alcanza ni la fe de un grano de mostaza.

De forma contundente, Kierkegaard no realiza ninguna mediación o concesión posterior a fijar el esquema del doble movimiento de la fe. Esto lleva a imaginar dos cosas: o sus anteriores afirmaciones sobre la fe del sacrificio de Isaac fueron un error de escritura, y tuvimos a un Kierkegaard desprevenido y somnoliento, o las nuevas afirmaciones sobre la fe constituyen una crítica radical. Evidentemente, es más plausible y probable la segunda posibilidad. En este sentido, Kierkegaard es tan crítico que ni siquiera admite que la recuperación de Isaac fuera el mayor acto de fe. No es concebible pensar que Abraham tuvo momentos en 
donde su fe fuera probada con mayor dificultad. Ni existe la categoría dialéctico-cualitativa de "la fe de este momento" contra la "fe de este otro momento"; ni la categoría cuantitativa de "menos fe" y "más fe". Ni lo uno ni lo otro, pues, según el danés, el padre de Isaac concentró su fe únicamente en un deseo. No hay que confundirse, en la historia de Abraham los milagros no sucedían una tras otro, como en la de Cristo y, aunque parezca increíble, no todas las palabras de Dios son necesariamente una invitación a la fe.

Junto con Kierkegaard, Green dice del padre de la fe y de las generaciones: "Abraham makes these two movements. He obeys God's command and willingly relinquishes Isaac. Simultaneosly, he continues to believe that God will not demand Isaac of him, and that he will again enjoy his son's presence in this life" ${ }^{24}$ Nótese que el sacrifico acontece por la fuerza extraordinaria y voluntaria del propio individuo y, llegado el caso de pedir cuentas, habría que dirigirse a él y no a Dios. Entretanto, que nunca nadie se canse de repetir que el telos máximo de la fe cristiana, el fin que conduce todos sus pensamientos, es buscarle "absurdamente" a la ética (puesto que es imposible) el Isaac que hace unas horas ha sido sacrificado. De donde sea y como sea, el milagro es darle a la ética su Isaac. En palabras de Green, hay que creer en la omnipotencia de Dios sólo cuando la ética está en el horizonte y el nombre de Dios próximo a ser "bueno". Para el sacrificio, en cambio, sólo son requisitos la genialidad y la persona de corazón enorme, pero jamás el milagro divino.

Si no es suficiente que algo impensable sea posible por la fe, entonces tampoco lo es que la fe sea una fe de absurdos e imposibles. Ahora bien, también es cierto que en Temor y temblor la fe comienza cuando comienza lo "absurdo" (en danés Absurde) y su posibilidad. Sobre esto, Bektovic 
resalta que en Kierkegaard "every movement offaith presumes a tension and a risk, understood as a leap out into the unknown or, as Johannes de Silentio says, a leap into the absurd". ${ }^{25}$ Igualmente, Powell afirma, sin ahorrarse palabras para el escándalo: "Faith is not believing in the possible, it is holding firm that the impossible is true, that the impossible is the only possible outcome. In the absurd faith becomes possible" ${ }^{26}$

El sacrificio de Isaac no encuentra otra manera de ser si no es con razones imposibles. Es un sacrificio que, pese a toda la bondad del mundo, traspasa y derrumba la ética. Siempre que se repitan los acontecimientos del monte Moriah, serán hechos fuera del nivel humano que, en cuanto nivel, está más homogéneo dentro de la ética. Siendo así, el sacrificio de Isaac es una cosa sobrehumana, ni más ni menos. En específico, lo sobrehumano equivale a mirar al cielo, encontrar al Dios cristiano y tener fe en él. Pero, por extraño que parezca, Kierkegaard coloca en el lugar de lo sobrehumano lo humano; es decir, dispone ahí la autonomía de la voluntad personal y la "resignación infinita" (uendelige Resignation). Es por demás extraño, porque si lo absurdo es efectuado por vías humanas o, más todavía, por un esfuerzo extraordinariamente humano, entonces no sería la trascendencia que Kierkegaard quiere establecer para situar un más allá de lo conocido en el monte Moriah. La resignación no ayuda en nada a mantener y nutrir el concepto de lo absurdo. Del sacrificio de Isaac, Curry y Vann dicen sobre Abraham:

25 Traducción libre: "todo movimiento de fe supone una tensión y un riesgo, entendido como un salto hacia lo desconocido o, como dice Johannes de Silentio, un salto hacia lo absurdo". Safet Bektovic, "The doubled movement of infinity in Kierkegaard and in Süfism", Islam and Christian-Muslim Relations 10,3 (1999): 329.

26 Traducción libre: "La fe no cree en lo posible, se mantiene firme en que lo imposible es verdad, que lo imposible es el único resultado posible. En lo absurdo la fe se hace posible”. M. Powell, "A tale of Two Abrahams: Kafka, Kierkegaard, and the Possibility of Faith in the Modern World”. The Heythrop Journal 53.1 (2012): 65. 
Si él hubiera permanecido solamente en el movimiento de la resignación, habría podido explicar su enigmática y terrible circunstancia de un modo inteligible para nosotros. El mismo Johannes considera la posibilidad de detenerse en este punto y describe en detalle cómo sería esta situación. ${ }^{27}$

En una nota a pie de página, ambos autores se muestran preocupados al comentar: "Pareciera que Johannes considera al movimiento de infinita resignación como un movimiento lógico; y no, como sugiere la interpretación propuesta, como un movimiento que es prerrequisito temporal del movimiento de la fe”. En sintonía con los temas discutidos, Curry y Vann consideran problemático que el sacrificio de Isaac, el primer movimiento hacia la fe, tenga elementos que resistan las fuerzas humanas. En teoría, lo que conduce hacia la fe debería comenzar a quebrar la medida humana justo en su último instante. Si con el esquema del doble movimiento Kierkegaard no propone una oposición cualitativa entre lo que es y no es fe, sino el proceso y camino hacia ella, debería suponerse que el primer movimiento alumbraría en sí las condiciones del próximo acto. ¿De dónde proviene el carácter absurdo del segundo movimiento? En efecto, del primero, que comenzó a ser absurdo. A raíz de estas ambigüedades, es necesario preguntarle al autor de $O$ lo uno o lo otro si, al fin de cuentas, el sacrificio de Isaac es o no es algo absurdo, y si es o no un acto de fe.

Para ir al fondo de la cuestión, el punto de partida es considerar que en Temor y temblor Kierkegaard contempla ambas tesis sobre el sacrificio de Isaac. Reconoce, por un lado, que este sacrificio es algo absurdo y un hecho de innegable fe. Por otro, que lo absurdo no es criterio suficiente para pensar la esfera sobrenatural de la fe cristiana. En este último lado

27 D. Curry y W. Vann, "La angustia de Abraham: un análisis del argumento central de Temor y temblor", Areté 7.1 (1995): 15-16. 
es donde vemos su procedimiento de "naturalizar humanamente" el sacrificio de Isaac, para desplazar de allí el espíritu de la fe. De las dos tesis, predomina la última. Una vez afirmada, Kierkegaard no deja caer la tesis, según la cual, la fe sólo puede consistir en la recuperación de Isaac y en todo absurdo que tenga como telos el de la ética. La nueva tesis es perfecta, el problema y el detalle es haber afirmado antes algo contrario que jamás volvió a considerar.

Es innegable que el danés reconoce y llega a ser consciente de que la fe, en su sentido más propio, es la experiencia de todo lo sobrenatural y sobrehumano que transgrede sin problema los intereses de la ética. Esta experiencia religiosa tiene todas las condiciones para santificar y convertir la muerte de la ética (de Isaac) en un bien. La fe en Dios no necesariamente mantiene encendido el fuego de la ética y, como todo acto mistérico, ${ }^{28}$ el sacrificio de Isaac demanda que Abraham alce los ojos al cielo para encontrar algún apoyo en la omnipotencia divina.

Luego Kierkegaard cambió su tesis sobre la fe y emprendió una crítica de la primera tesis a través del esquema del doble movimiento. En este punto, ya no hay nada de fe en el sacrificio de Isaac, porque ésta es el absurdo que recupera y resucita al amor, al prójimo y a la ética. Es lo que trae a la vida, después del terror que puede causar una conciencia humana resignada, la salvación de las cosas amadas por la ética. Lo sobrehumano y divino no necesariamente pretenden santificar la perdida de lo humano, es posible que ambos conceptos contraigan el poder y el deber de ser una forma superior para conservar la ética humana. Kierkegaard opta por esta posibilidad al hacer que la ética sobreviva en esferas

28 En Temor y temblor, los actos de fe no radican en la maldad ética. La sola maldad como el solo bien están al alcance del enjuiciamiento humano. Lo que hace a una persona alzar los ojos al cielo es la paradoja de ambos, lo absurdo, el hecho de que el mal sea un bien. Estas condiciones se cumplen en el sacrificio de Isaac. 
superiores y evitar que se torne en un fantasma ambulante. Así que la fe es lo absurdo y lo ético; es lo que cree con todo el corazón que la ética triunfará en el absurdo y no se perderá con nobleza. Sólo así se cree con el corazón. Habría, entonces, que ubicar la fe en la resurrección de Isaac, como el único movimiento absurdo — volver de la muerte- que mantiene con entereza y plenitud las exigencias éticas. Es el único movimiento capaz de ser fe y, nótese bien, capaz de ser ético. Kierkegaard ya lo había dicho: la fe es la suspensión teleológica de la ética. En cuanto tal, la fe termina siendo la vía fuera del entendimiento humano para llegar a ser ético; es decir, la vía superior para llegar a la ética.

La crítica, por tanto, consiste en que Kierkegaard no considera la fe cristiana como algo necesariamente ético y, ante la falta de necesidad, hay que colocar otra esfera en el núcleo de su telos. En sí misma, la naturaleza sobrehumana de la fe no alcanza a proteger el telos de la eticidad y la fe en Dios puede realizarse perfectamente en el llanto y el dolor de la ética. Todo el problema se debe a que Dios establece las cosas, de tal modo que el sacrificio de Isaac es ya, de por sí, un acto religioso, cristiano y de fe. Así, es inviable que alguien hable de la fe cristiana como si lo hiciera de ética. La ética está antes o después de lo cristiano, no en lo cristiano mismo. De ahí la necesidad de traerle al cristianismo el telos contrario de la ética, como momento "no religioso" que limita las pretensiones originales y absolutas de la fe.

A fin de hibridar ambos telos, Kierkegaard reformula el concepto al interpretar el sacrificio de Isaac. Como se ha observado, este sacrificio aparece primero como un acto de fe y luego deja de serlo. Esta inversión provocó que el sacrificio de Isaac fuera convertido en un acto completamente humano y racional, que no conllevaría nada sobrenatural, aunque provenga de la esfera divina y fuera ordenado por el Dios de Abraham. Estas reformulaciones se resumen en una de las afirmaciones más contundentes de Kierkegaard sobre Abraham, “y creyó para esta vida. Porque si su fe se hubiera referido solamente a la vida futura, no le 
habría costado apenas nada despojarse de todo para abandonar en seguida un mundo al cual ya no pertenecía”. ${ }^{29}$ Al final y en el fondo, todos estos giros conceptuales tienen como base la suposición ética de que Dios es bueno. Sagi lo muestra en su repaso por las explicaciones de Evans: "As Evans has shown, in Fear and Trembling Kierkegaard indeed assumes that God is good. Abraham's faith reflects this assumption". ${ }^{30}$ Este supuesto, como cualquier otro, se ubica "antes que todo", la lectura de la fe se ve transformada por ello.

\section{El concepto de la angustia}

En 1844, Kierkegaard vuelve a retomar sus inquietudes sobre la fe en $E l$ concepto de la angustia; esta vez, cuando asume la interpretación bíblica de la génesis del pecado original. Su objetivo no es entender el pecado, sino comprender cómo se dio el paso desde "la inocencia entre el bien y el mal" (en danés Uskyldigheden mellem Godt og Ondt) al "pecado" (Synd).

Siguiendo las pistas de las Sagradas Escrituras, Kierkegaard explica que las consecuencias de haber alcanzado el conocimiento de lo bueno y lo malo fueron dos: "que el pecado vino al mundo y que quedó establecida la sexualidad". ${ }^{31}$ De origen latino, el término sexualidad (sexus o sectus: corte /dad: cualidad, propiedad) implica hablar de separación y diferenciación, en contraste con un estado que permanece sin oposición. Cuando surge la sexualidad (en danés Sexuelle) cada ser humano comienza a separarse de aquello que está delante de sí y se da la fragmentación de una totalidad indiferenciada. Desde ahora y en adelante "aparece la

$29 \quad$ K. 2010, 638. SKS, FB, 116.

30 Traducción libre: “Como ha demostrado Evans, en Temor y temblor, Kierkegaard asume que Dios es bueno. La fe de Abraham refleja esta suposición”. Ayi Sagi, "The Suspension of the Ethical and the Religious Meaning of Ethics in Kierkegaard's Thought", International Journal for Philosophy of Religion, vol. 32, núm. 2 (1992): 84.

$31 \quad$ K. 2007, 112. SKS, BA, 353. 
diferencia entre yo mismo y todo lo demás mío". ${ }^{32}$ Con más contundencia, aparecen los límites. Hay algo que está al frente o al otro lado que no puede ser integrado, tomado y acogido sin traer negatividad. Así, lo máximo a conseguir será una unidad negativa, en donde el bien común no es el bien de los otros. La sexualidad es el principio de la contradicción o de la mítica guerra de todos contra todos. En este escenario armagedónico, el ser humano se convierte para el más próximo de su especie en homo homini lupus (el hombre es el lobo del hombre), y ocurre con frenesí la lucha por la autosubsistencia. En tal hostilidad, no hay manera de comprender e incluir lo diferente sin que represente algún mal. Con la sexualidad aparece la lucha entre lo masculino y lo femenino, entre lo animal y lo humano, entre la especie y el individuo, entre cualquiera y toda diferencia.

En retrospectiva, antes de abandonar el estado de inocencia y haber conocido el bien y el mal, "el hombre no es animal, pero tampoco es propiamente hombre, y al hacerse hombre no resulta tal sino en la medida en que también es animal". ${ }^{33}$ A diferencia de la sexualidad, "En este estado hay paz y reposo [...] pues sin duda que no hay nada contra lo que luchar". ${ }^{34}$ Nunca hubo enemigos en frente, según Kierkegaard, porque el ser humano podía ser al mismo tiempo animal. Cualquier otra diferenciación o separación venía a ser un velo transparente que no obstaculizaba; incluso, cuando no era una cosa, no por ello era la otra, pues no había límite para el ser de las cosas. Se podía ser esto, se podía ser aquello, se podía ser ambos, sin que nada tuviera significado de contrariedad o hubiera que ir a la guerra para matar primero al enemigo. De manera más enfática, "Sólo con la sexualidad está puesta la síntesis en 
cuanto contradicción". ${ }^{35}$ Desconocida la ideología sexual, todo cabía en el paraíso edénico y los ojos no se asombraban por ver cosas que no eran ellos. Como explica Shestov: "Tal vez Kierkegaard habría debido expresarse de un modo más concreto y decir que la libertad del hombre inocente no conoce ningún límite. Esto hubiese estado conforme con lo que antes nos había dicho en pleno acuerdo con la Biblia: que todo es posible para Dios". ${ }^{36}$

Efectivamente, todo era posible en la inocencia del bien y del mal. Allí no había formas definidas y el cuadrado hubiera podido ser circular. Todo era comprehendido y las cosas podían ser de muchas maneras. No aparecía la diferencia "entre yo mismo y todo lo demás mío" (en danés mellem mig selv og mit Andet sat), ni la oposición angular entre el bien y mal. El paraíso de Dios estaba vacío de las categorías del entendimiento y no existían los diccionarios ni los significados. Absolutamente, como jamás en la imaginación, todo era permitido sin más prohibición. Siguiendo a Kierkegaard, Marino afirma: "When Godprohibits Adam to eat from the tree or else surely die, Adam cannot, in a sense, understand Him, for he knows neither good and evil nor death". ${ }^{37}$ En palabras de Kierkegaard: "Por lo pronto, Adán no tiene ni idea de qué es lo que puede; en otro caso se supondría ciertamente [...] lo que viene después, a saber, la distinción entre el bien y el mal". ${ }^{38}$

Según Kierkegaard, sin embargo, la inocencia del bien y del mal debe quedar anulada en el mismo momento de ser nombrada. "La inocencia no es una perfección que haya que echar de menos, pues el que tiene de-

\footnotetext{
$35 \mathrm{~K}, 2007,114 . \mathrm{SKS}, \mathrm{BA}, 354$.

36 Shestov, Kierkegaard y la filosofía existencial, 117.

37 Traducción libre: “Cuando Dios prohíbe a Adán comer del árbol o de lo contrario morir, Adán no puede, en cierto sentido, entenderlo, porque no conoce el bien, el mal ni la muerte". Gordan D. Marino, "Anxiety in The Concept of Anxiety", en The Cambridge Companion to Kierkegaard, A. Hannay, Gordon D. Marino, eds. (Cambridge: Cambridge University Press, 1998), 308-328.

$38 \quad$ K. 2007, 106. SKS, BA, 350.
} 
seos de inocencia demuestra bien a las claras que la ha perdido" ${ }^{39} \mathrm{El}$ hecho de recordarla y extrañarla es prueba de haberla perdido. La inocencia es algo de lo cual se huye; algo así como una gigante grieta en estado de fuga que pierde consistencia y presiente el escape. Esto supone que su estado de paz y de reposo es una felicidad no tan feliz. Un paso más y la pregunta es latente, ¿qué imperfección amenaza en la inocencia del bien y del mal? Ciertamente no hay amenaza alguna, en ella hay "paz y reposo” (Fred og Hvile), pero “...también hay otra cosa, por más que ésta no sea guerra ni combate [...] ¿Qué es entonces lo que hay? Precisamente eso: ¡nada!”. ${ }^{40}$ Esa "nada” (en danés Intet) tan insospechada y movediza, esa otra cosa tan difícil de observar a primera vista, muy seguramente provocó la pérdida de la inocencia.

Pero, ¿cómo intuir nada si todo es posible en la inocencia del bien y del mal? Sucede que mientras esto sea posible, pero también aquello, o ambos sean posibles, entonces, ni lo uno ni lo otro serán posibles, porque al afirmar algo se abre otra manera de ser. Al grado de marcar su efecto rítmico, la "...posibilidad pone de manifiesto una nueva posibilidad como consecuencia suya". ${ }^{41}$ Semejante flujo de creación es incesante y repetido, la "posibilidad" (en danés Mulighed) ya no es esa posibilidad, dado que lo nuevo no continúa más nuevo que en la desaparición actual de su novedad. La expresión cotidiana: "en la medida de lo posible" acude como testigo del fenómeno. Usada cuando alguien quiere hacer algo en cuanto le sea mínimamente posible, a la más insignificante y diminuta oportunidad, la expresión revela que el hablante piensa como si no fuera a quedar nada. De dicho popular a juicio reflexivo, esa expresión descubre que la posibilidad se desvanece rápido, por suponer siempre 
nuevas maneras de ser. "En la medida de lo posible" señala que alguien queda pendiente de encontrar la aguja en un pajar, es decir, en medio de la nada y la indeterminación.

Por consiguiente, el mundo de la posibilidad es el mundo del ser-en-suspenso, allí las cosas todavía no son o, con más exactitud, las cosas no permanecen más de lo que se desvanecen. En este mundo es imposible ver algo en el sentido de verlo siempre a la vuelta y verlo ahí, como siendo y no siendo, la posibilidad "desaparece tan pronto como le vas a echar la mano encima, quedando sólo una nada que no puede más que angustiar". ${ }^{42}$ Desde la pregunta hecha, el lenguaje no ha parado de revelar la nada que oculta la posibilidad: desaparición, negatividad, indeterminación, ni esto ni aquello ni ambos. La posibilidad es una categoría de la nada y de la única imaginable: la que no habita la nada, ni el ser.

Hasta aquí, aunque sería coherente dar todo como un hecho, Shestov nota que la interpretación bíblica de Kierkegaard conduce hacia una contradicción inusual. Tal vez hasta el momento no es sospechoso que la inocencia del bien y del mal sea "la nada que engendra la angustia" (Intet Det føder Angest); no obstante, Shestov cuestiona: “¿Quién nos ha dado el derecho de explicar de este modo la inocencia? Esto no consta en la Biblia". ${ }^{43}$ Para entender a Shestov es preciso recordar que Kierkegaard sitúa el pecado en el cambio desde un estado anterior a conocer el bien y el mal. Además, debe tenerse en cuenta que el cristianismo no evade el pecado, pero le opone una cosa contraria que se muestra como su antídoto: la fe. Esto último lo recuerda Kierkegaard a la menor ocasión: "No, lo contrario del pecado es la fe, y por eso en la epístola a los Romanos $(14,23)$ se nos dice: 'Todo lo que no procede de la fe es pecado'. Éste es, desde luego, uno de los conceptos más discriminativos de todo el

\footnotetext{
$42 \quad$ K, 2007, 102. SKS, BA, 347-348.

43 Shestov, Kierkegaard y la filosofía existencial, 116.
} 
cristianismo". ${ }^{44}$ Si tanto se oponen, cuando Kierkegaard dice que el pecado vino al mundo cancelada la inocencia, debe suponerse que el estado anterior era guiado por la fe, pues el pecado sólo existe si deja de tener procedencia directa de su antídoto. Además, aquello que sea la fe, también es vista por Kierkegaard en aquel estado anterior. Descubrió que el concepto de la inocencia ignora todo, menos la absoluta posibilidad, y escribe lo siguiente de la fe: "El creyente posee el eterno y seguro antídoto [...] es decir, la posibilidad; ya que para Dios todo es posible en cualquier momento. Ésta es la salud de la fe". ${ }^{45}$ Por tanto, Shestov considera que en El concepto de la angustia Kierkegaard explica la fe con unas categorías muy diferentes a las escrituras cristianas. El cambio fundamental radica en convertir la omnipotencia del "todo es posible" en nada y, por tanto, en algo ilusorio que justifica la categoría de la inocencia.

A causa de la ilusión, Kierkegaard confecciona un dispositivo que tiene la función de crear una fisura en el paraíso de la fe y motivar la huida. Según el autor danés: "En la inocencia no está el hombre determinado como espíritu, sino sólo anímicamente determinado en unidad inmediata con su naturalidad. El espíritu está entonces en el hombre como sońando. Esta concepción concuerda perfectamente con la de la Biblia”. ${ }^{46}$ Lo revelador de estas afirmaciones radica en mostrar que, en el mundo de la fe, el ser humano no vive como "espíritu" (Aand). Una vida de tal magnitud es equivalente a deambular en la inferioridad de lo natural, en el aquí junto a este árbol y el ahora que mira el reloj sin darse otra cualidad superior. En tal condición, el espíritu del ser humano sueña y duerme porque no ha llegado a una idea clara de sí mismo. De no ocurrir el cambio, la humanidad vivirá en una ilusión que no balancea la medida con un despertar.

\footnotetext{
$44 \quad$ K. 2008, 110. SKS, SD, 196.

45 K. 2008, 60. SKS, SD, 155.

$46 \quad$ K. 2007, 101. SKS, BA, 347.
} 
Semejante tesis es oscura y provocativa, porque en el pensamiento de Kierkegaard "Mennesket er Aand [El hombre es espíritu]" ${ }^{47}$ y, tarde que temprano, la humanidad no puede comenzar su historia sin acontecer su despertar espiritual. Justamente, Marino capta la urgencia del espíritu al decir que Kierkegaard: "Over and over, he reminds us that were it not for the fact that we are spirit, anxiety, despair, sin, and faith would be impossible ${ }^{48}$ En cuanto es el factor esencial para la conformación de lo humano, hasta el final de los tiempos y por todos los medios, el espíritu tendrá la tarea de llegar a ser lo que es y, al tiempo, del despertar. Al proceder así, Kierkegaard crea razones suficientes y exigencias inevitables para dar el paso de la fe hacia el conocimiento del bien y del mal. Para Münnich, en este contexto plagado de cristianismo y lucha contra lo cristiano, la ecuación es: "El concepto de la angustia [...] identifica la caída del hombre con el despertar de lo espiritual". ${ }^{49}$

Ahora bien, a fin de entender la totalidad de lo implicado en esta crítica de Kierkegaard a la fe cristiana, debe considerarse que la inocencia edénica apunta en todo momento a la cuestión de la ética. En un escrito titulado: El libro de Adler (no publicado en vida por el danés y aún sin traducción al español), Kierkegaard declara: "La naturaleza es indiferente a la distinción que para la ética lo es todo: la distinción entre el bien y el mal". ${ }^{50} \mathrm{Y}$ ya en las obras para el público, Kierkegaard vuelve a confirmar

$47 \quad$ K. 2008, 33. SKS, SD, 129.

48 Traducción libre: "Una y otra vez, nos recuerda que si no fuera por el hecho de que somos espíritu, la angustia, la desesperación, el pecado y la fe serían imposibles". Marino, "Anxiety in The Concept of Anxiety", 315.

49 Susana Münnich, "Kierkegaard y el pecado original de la filosofía”, Revista de Filosofía, vol. 27-28 (2016): 89-103.

50 Traducción del danés al castellano por Anna Fioravanti (cofundadora de la Biblioteca Kierkegaard Argentina y colaboradora en la presentación y traducción al castellano de la obra El Instante de Kierkegaard por la editorial Trotta). Del original danés: “Naturen er netop ligegyldig mod den Distinktion som er Ethiken Alt: den mellem Godt og Ondt". SKS, BOA, 239. 
que el bien y el mal suponen el carácter de la eticidad: "El que considera la personalidad éticamente encuentra de inmediato una diferencia absoluta, la que existe entre el bien y el mal". ${ }^{51}$ Lo cual quiere decir que Kierkegaard interpreta el reino edénico bajo la clave de la ausencia ética o, mejor, que todo lo edénico se constituye con la inocencia de lo ético. Como aquí no está presente la conciencia ética del bien y del mal, que suponía un límite ${ }^{52}$ para lo religioso en Temor y temblor, es comprensible que el ser humano viva sin restricciones la experiencia de que todo es posible para Dios. No obstante, este "todo" absoluto, carente de eticidad, está directamente relacionado con la nada y el sueño del espíritu. Estas relaciones son el punto de inflexión y el motivo de crítica que ha llevado a una reformulación de todo lo cristiano.

La crítica tiene por objeto la gravedad que representa la inocencia ética. A raíz de ello, como sugiere Münnich, en El concepto de la angustia parece no importar que el ser humano caiga en el pecado y la sexualidad, si a cambio tiene lugar el despertar ético de la conciencia del bien y del mal. La tarea eterna es pasar del sueño a un amanecer que desmienta la paz de la infinita posibilidad. Si en realidad es todo, si todo es posible, entonces ello esconde una bondad aparente, porque en cualquier momento ni lo uno ni lo otro, en cualquier momento, nada. De repente, lo que se tiene, Dios lo quita, lo arranca y lo desaparece bajo el argumento de su cielo insondable. De la nada, la realidad se vuelve fantástica: nada queda. Es cierto, los seres humanos pierden cosas a diario, pero se consuelan pensando que una ley les garantizará la posesión de algo mayor. Desde la óptica cristiana no hay ley que valga y lo que se recupera puede

$51 \quad$ K. 1995, 97. SKS, EE2, 216.

52 El concepto de la angustia corrobora que la ética es efectivamente el límite de la fe cristiana. Los factores limitantes, como el pecado y la sexualidad, son consecuencias que, en tanto tal, son posteriores a despertar la conciencia ética del bien y del mal. En realidad, es entre el dormitar y el despertar de esa conciencia ética que se sitúa la conformación o el lado opuesto de lo cristiano-religioso. 
volverse a perder (reminiscencia clara de Isaac). "Y ¿qué efectos tiene la nada? La nada engendra la angustia". ${ }^{53}$ La angustia, dice Kierkegaard, es "una angustia suave, una dulce ansiedad..., y también se dice: una angustia extraña, una angustia tímida". ${ }^{54}$ Ansiedad, extrañeza y timidez son todas ellas categorías de lo terrorífico, del terror. Así es como la angustia por la nada llega a ser una categoría estrictamente cristiana y religiosa que aterra. Más aún, así se convierte en lo que desmiente tanta paz y reposo en el mundo edénico.

Por tanto, la crítica de Kierkegaard consiste, una vez más, en reformular el concepto de fe por falta de eticidad y de límite. En lugar de mostrar, como lo hacen las escrituras, la bondad (valde bonum: todo era bueno) y la omnipotencia de la fe en el mundo edénico, Kierkegaard decide mostrar la inocencia, la nada y la angustia de la posibilidad. Gracias a ello, la ilusión termina y el ser humano, en cuanto espíritu, atesora la tarea pendiente de un despertar inevitable.

\section{Conclusiones}

En definitiva, es viable decir que Temor y temblor y El concepto de la angustia exponen críticas al concepto de la fe. En ambas obras, Kierkegaard realiza movimientos irregulares y reformulaciones al concepto. En el caso de Temor y temblor, el sacrificio de Isaac es la pieza decisiva para el giro conceptual. Pese a todos los supuestos de fe que el sacrificio de Abraham implica, por cuanto no es posible justificarlo por vías éticas o humanas, Kierkegaard decide negarle la fe y, por si fuera poco, transformarlo en un acto de valor humano. La razón para estos cambios no es azarosa. Desde el comienzo, el objetivo de la obra es hacer que el telos de la fe sea el telos

\footnotetext{
53 K. 2007, 101. SKS, BA, 347.

54 K. 2007, 102. SKS, BA, 348.
} 
de la ética, de una ética concebida como otra esfera y con otros intereses opuestos a los de la fe. De manera que los actos de fe son criticados apenas sobrepasan los intereses de la ética. Contra todos los pronósticos, no hay nada de fe en el sacrificio de Isaac, la fe está en recuperar lo sacrificado en virtud del misterio (Dios); es decir, en el momento que la ética, sin saber cómo, recuperó lo que más amaba. El resultado total consiste en que la fe se reformula en Temor y temblor a partir de una teleología ética, de afirmaciones irregulares sobre la fe y de una humanización de lo divino.

En El concepto de la angustia, la interpretación que Kierkegaard realiza sobre la narración cristiana del Edén bíblico es la pauta para encontrar otra reformulación al concepto de fe. En el Edén se cumplen totalmente las premisas máximas de la fe. En primer lugar, Kierkegaard es consciente de que "todo lo que no procede de la fe es pecado" y lo cierto es que en el Edén bíblico no existe el pecado. En segundo término, en el Edén se cumple como nunca la premisa de que para Dios todo es posible en cualquier momento. Para Kierkegaard, esto último se da por la inocencia de los límites éticos del bien y del mal. En este contexto, el pensador danés sigue la tesis de las Sagradas Escrituras, según la cual, en el Edén todo era bueno (valde bonum), pues había paz y reposo. No obstante, luego surge el problema de que si todo es posible, entonces nada lo será, porque en cualquier momento y por la misma vía, Dios puede quitarlo todo en favor de otra posibilidad. Entonces, en lugar de paz y reposo, el reino absoluto de la fe es la nada que engendra el terror de la angustia; en otro sentido, es una ilusión. A raíz de esta ilusión y engaño, Kierkegaard considera que Adán y Eva, como cualquier otro ser humano, tienen la tarea eterna de acabar con el sueño paradisiaco del Edén y arribar a la conciencia ética del bien y del mal. El resultado total consiste en que Kierkegaard reformula la fe de la escritura bíblica al verla, en primer lugar, bajo las categorías no cristianas de la inocencia, la nada y la angustia y, en segundo, al apuntar de nuevo hacia una teleología ética. 
En suma, en Temor y temblor y en El concepto de la angustia Kierkegaard critica que la fe cristiana llegue a tener un telos tan absoluto que no considere otras esferas existenciales, como la ética y su distinción absoluta entre el bien y el mal. Tanto en su presencia, como en su ausencia (caso de la inocencia edénica), la ética de Kierkegaard levanta su voz contra la fe y termina siendo factor de crítica esencial para los conceptos cristianos. 


\section{Referencias}

Bektovic, S. "The doubled movement of infinity in Kierkegaard and in Süfism". Islam and Christian-Muslim Relations 10:3 (1999): 325337.

Curry, D. y W. Vann. "La angustia de Abraham: un análisis del argumento central de Temor y Temblor". Areté 7.1, (1995): 5-26.

Fremstedal, R. "Kierkegaard's Views on Normative Ethics, Moral Agency, and Metaethics". En: A Companion to Kierkegaard, J. Stewart ed., 113-125. Nueva Jersey: Wiley Blackwell, 2015.

González, D. "Kierkegaard's Skepticism”. En: A Companion to Kierkegaard, J. Stewart, ed., 126-137. Nueva Jersey: Wiley Blackwell, 2015.

Green, R. M. "Developing Fear and Trembling". En: The Cambridge Companion to Kierkegaard, A. Hannay y G.D. Marino, ed., 257281. Cambridge: Cambridge University Press, 1998.

Grøn, A. "La ética de la repetición”. Enrahonar: quaderns de filosofía, vol. 29 (1998): 35-45.

Guerrero, Luis. "Los niveles de interpretación de Temor y temblor".En Søren Kierkegaard Senderos existenciales, coordinado por Luis Guerrero, 37-40. Ciudad de México: Sociedad Iberoamericana de Estudios Kierkegaardianos, 2013.

Kierkegaard, S. El concepto de la angustia. Herederos de Demetrio Gutiérrez Rivero, trad. Madrid: Alianza Editorial, 2007. . Estética y ética en la formación de la personalidad. Armand Marot, trad. Buenos Aires: Nova Editorial, 1995. . La enfermedad mortal. D. Gutiérrez Rivero, trad. Madrid: Trotta, 2008.

. Søren Kierkegaard Skrifter. N.J. Cappelorn, J. Garff, J. Knudsen, J. Kondrup y A. McKinnon, eds. Kobenhavn: Gyldendal, 19972012. 
. Temor y temblor. D. Gutiérrez Rivero, trad. Madrid: Gredos, 2010.

Marino, M. D. "Anxiety in The Concept of Anxiety". En The Cambridge Companion to Kierkegaard, A. Hannay, G.D. Marino, eds., 308328. Cambridge: Cambridge University Press.

Münnich, S. "Kierkegaard y el pecado original de la filosofía”. Revista de Filosofía, vol. 27-28 (2016): 89-103.

Powell, M. "A tale of Two Abrahams: Kafka, Kierkegaard, and the Possibility of Faith in the Modern World". The Heythrop Journal 53, (2012): 61-70.

Sagi, A. "The Suspension of the Ethical and the Religious Meaning of Ethics in Kierkegaard's Thought". International Journal for Philosophy of Religion, vol. 32, núm. 2 (1992): 83-103.

Shestov, L. Kierkegaard y la filosofía existencial. José Ferrater Mora, trad. Buenos Aires: Editorial Sudamericana, 1952. 